Article

\title{
Polylactic Acid Improves the Rheological Properties, and Promotes the Degradation of Sodium Carboxymethyl Cellulose-Modified Alkali-Activated Cement
}

\author{
Huijing Tan, Xiuhua Zheng *, Chenyang Duan and Bairu Xia \\ School of Engineering and Technology, China University of Geosciences (Beijing), Beijing 100083, China; \\ thj0528@163.com (H.T.); chyangd@sina.com (C.D.); boruxia@sina.com (B.X.) \\ * Correspondence: xiuhuazh@cugb.edu.cn; Tel.: +86-10-8232-2624 \\ Academic Editor: Kamel Hooman \\ Received: 29 May 2016; Accepted: 7 October 2016; Published: 14 October 2016
}

\begin{abstract}
In consideration of the insolubility in water, sensitivity to heat and wide application in the oil and gas industry as a degradable additive, this paper introduces polylactic acid (PLA) to a self-degradable temporary sealing material (SDTSM) to investigate its effect on the SDTSM performance and evaluate its potential to improve the rheological properties and further promote the self-degradation of the material. The thermal degradation of PLA, the rheological properties, compressive strength, hydrated products and water absorption of SDTSMs with different PLA dosages were tested. The analysis showed that the addition of $2 \%$ PLA increased the fluidity by $13.18 \%$ and reduced the plastic viscosity by $38.04 \%$, when compared to those of the SDTSM without PLA. PLA increased the water absorption of $200{ }^{\circ} \mathrm{C}$-heated SDTSM and had small effect on the types but decreased the hydrate products of $85^{\circ} \mathrm{C}$-cured SDTSM, and created plenty of pores in $200{ }^{\circ} \mathrm{C}$-heated SDTSM. PLA enhanced the self-degradation level of SDTSM by generating a large amount of pores in cement. These pores worked in two ways: one was such a large amount of pores led to a looser microstructure; the other was these pores made the water impregnate the cement more easily, and then made the dissolution of substances in the $200^{\circ} \mathrm{C}$-heated SDTSM progress faster to generate heat and to destruct the microstructure.
\end{abstract}

Keywords: self-degradable temporary sealing material; geothermal wells; polylactic acid; rheological properties; self-degradation

\section{Introduction}

The development of geothermal reservoirs usually encounters highly permeable formations that are either naturally fractured or created through stimulation operations [1-3]. To control the loss of drilling fluids, these fractures must be plugged during drilling and reopened for production when the drilling is completed. A temporary sealing material is required not only to plug the fractures at $85^{\circ} \mathrm{C}$, but also to self-degrade both in hot water at $200^{\circ} \mathrm{C}$ and when coming in contact with water during stimulation operations after the dry heat of $200^{\circ} \mathrm{C}$, depending on the conditions of geothermal wells [4]. Sugama [4,5] and Li [6] added sodium carboxymethyl cellulose (CMC) into sodium silicate-activated slag/Class C fly ash cementitious materials, to develop a self-degradable temporary sealing material (SDTSM), which could meet these requirements.

The alkali-activated fly ash/slag cements, prepared from industrial by-products of the fly ash and slag with pozzolanic properties has an ability to withstand the hot acidic environment caused by the combination of concentrated dihydrogen sulfide $\left(\mathrm{H}_{2} \mathrm{~S}\right)$ and carbon dioxide $\left(\mathrm{CO}_{2}\right)$ [4]. The cements are characterized by their high mechanical performance, low energy cost and low pollutant gas emission, 
less environmental deterioration, and their thermal resistance together with significantly reduced energy costs $[7,8]$.

CMC, which is commonly used as an additive in water-based drilling fluids to control fluid loss, can significantly increase the viscosities of fluids $[9,10]$. However, the high viscosity of cement reduces its pumpability and should be kept low enough during the entire cementing operation [11]. PLA is sensitive to heat and will obviously degrade when the temperature is above $200{ }^{\circ} \mathrm{C}$ [12]. Additionally, in consideration of PLA's insolubility in water and application as a degradable polymer, this paper introduced PLA to SDTSM aiming to improve the rheological properties and further promote the self-degradation of the material.

PLA has been widely used in medical field, daily life and oil \& gas industry as a degradable additive. In medical operations, PLA is applied as an additive in bone cement, which will degrade to cause high porosity of cements when it contacts with body fluids, thereby providing inter-connective channels for the bone [13-15]. As a green environmental material, PLA was also used to manufacture daily products, fresh-food packages, shopping bags and bed sheets, etc., replacing the petroleum-based products $[16,17]$. In oil and gas industry, PLA is combined with other materials to form degradable particulates in temporary sealant slurry for plugging the preexisting fractures, and then degraded to remove the sealer after the re-fracturing operations [18]. PLA is used to coat proppant sand or gravel pack sand, which will degrade to leave conducting channels at the end of a fracturing or gravel packing operations [19]. It is also employed to form degradable diverter plugs for reducing the time for operation, equipment standby and fluid flow back and reducing the risk of premature setting of the fracturing plugs, by avoiding the need to drill out the plugs before production [20].

Thermogravimetric analysis (TGA) and Pyrolysis-gas chromatography/mass spectroscopy (Py-GC/MS) were employed to test the thermal decomposition properties of PLA. X-ray diffraction analysis (XRD) was used to study the hydrated cement products. The rheological properties, compressive strength, hydrated products and water absorption of SDTSMs with different PLA dosages were tested to investigate the influences of PLA on the properties of SDTSM. After immersing $200{ }^{\circ} \mathrm{C}$-heated samples in water for different times, the degradation of the samples was observed by a polarizing microscope and scanning electron microscopy (SEM). The compressive strengths were further determined to assess the level of degradation.

\section{Experimental Procedures}

\subsection{Materials}

The slag was obtained from Longang Trading Co. Ltd. (Tangshan, China). The Class C fly ash was supplied by Luyuan Power Resource Development Groups Co. Ltd. (Dongying, China). Sodium silicate was supplied by Qingdao Yousuo Chemical Technologies, Inc. (Qingdao, China). CMC was supplied by Yanxing Chemical Industry, Inc. (Renqiu, China). PLA was obtained from Changsheng New Materials Technologies, Inc. (Guangzhou, China) and typical values of its physical properties are listed in Table 1.

Table 1. Typical values of PLA's physical properties.

\begin{tabular}{cc}
\hline Physical Properties & Typical Values \\
\hline Density $\left(\mathrm{g} / \mathrm{cm}^{3}\right)$ & $1.25 \pm 0.05$ \\
Melting temperature $\left({ }^{\circ} \mathrm{C}\right)$ & $155 \sim 165$ \\
Glass transition temperature $\left({ }^{\circ} \mathrm{C}\right)$ & $56 \sim 60$ \\
Tensile strength $(\mathrm{MPa})$ & $\geq 5$ \\
Elongation at break $(\%)$ & $\geq 3.0$ \\
Impact strength $\left(\mathrm{kJ} / \mathrm{m}^{3}\right.$, Izod) & $1 \sim 3$ \\
\hline
\end{tabular}

The SDTSM formula, referencing the study of Sugama [4,5] and Li [6], had slag/Class C fly ash ratio of $80 / 20$ by weight, $6 \%$ sodium silicate and $1 \%$ CMC by total weight of the dry pozzolana cement. 
Water was added at a water/dry pozzolana cement ratio of 0.6 to prepare cement. The SDTSM without $\mathrm{CMC}$, i.e., the sodium silicate-activated slag/Class $\mathrm{C}$ fly ash cementitious material, was considered the control sample. To study the rheological behavior of SDTSM with different PLA dosages, $1 \%, 2 \%$, $3 \%, 4 \%, 5 \%, 6 \%, 7 \%, 8 \%, 9 \%$ and $10 \%$ PLA by the total weight of pozzolana cement were added into SDTSM. $2 \%, 4 \%, 6 \%, 8 \%$ and $10 \%$ PLA were added to examine the effects of PLA on the compressive strength, hydrate products, water absorption and self-degradation of SDTSM. The polymers and the dry pozzolana cements were blended thoroughly and uniformly prior to adding into water. These slurries were placed in air at room temperature for $72 \mathrm{~h}$, afterwards, all set cements were cured at $85^{\circ} \mathrm{C}$ for $24 \mathrm{~h}\left(85^{\circ} \mathrm{C}\right.$-cured), and some of these specimens were further heated for $24 \mathrm{~h}$ in an oven at $200{ }^{\circ} \mathrm{C}\left(200^{\circ} \mathrm{C}\right.$-heated $)$.

To evaluate the thermal decomposition of PLA in cement, PLA powder (4 g) was immersed into filtrate $(50 \mathrm{~mL})$ obtained by a API filter tester from the SDTSM slurry without PLA. The $\mathrm{pH}$ of the filtrate was 13.16. The filtrate with PLA was cured at room temperature for $72 \mathrm{~h}$ and at $85^{\circ} \mathrm{C}$ for $24 \mathrm{~h}$, and then filtered, washed, and dried for further testing.

\subsection{Measurements}

A Thermo Gravimetric Analyser (TGA) (TA instruments, New Castle, DE, USA) was used to test the decomposition of the non- and filtrate-treated PLAs. Tests were carried out in nitrogen atmosphere and air atmosphere with a heating rate of $10^{\circ} \mathrm{C} / \mathrm{min}$.

Py-GC/MS carried out on a pyrolyzer (Frontier Lab, Fukushima, Japan) and a gas chromatograph-mass spectrometer (Agilent, Santa Clara, CA, USA) was used to identify and quantify the volatile derivatives emitted by the decomposition of PLA. The chromatographic peaks were identified by referencing them to the NIST MS library and data in the literatures, by comparing their chromatographic retention times to those of the available reference chemical compounds.

Fluidity was measured according to Chinese national standard GB/T 8077-2012 [21]. A cone frustum (60 $\mathrm{mm}$ high with diameters of $36 \mathrm{~mm}$ in the top and $60 \mathrm{~mm}$ in the base), a glass plate, a stopwatch and a steel ruler were used to test the fluidity. The moist cone without water stains was placed on the clean glass plate. Then the cone was fully filled with cement slurry, lifted up vertically. Two maximal diameters in vertical direction of the slurry were measured after $30 \mathrm{~s}$. The shear stress $(\tau)$ of the samples at different shear rates $(\gamma)\left(5.11,10.21,170\right.$ and $\left.340 \mathrm{~s}^{-1}\right)$ were tested by a six-speed rotating viscometer (Haitongda, Qingdao, China) according to API Recommended Practice 10B-2 [22]. The accuracy of dial reading is $1.0^{\circ}$.

Compressive strength was tested according to Chinese National Standard GB 10238-2005 [23] and Chinese Petroleum and Natural Gas Industry Standard SY/T 6544-2010 [24] by using a YAW-300B servo universal testing machine (Chandler, Chengdu, China) with a loading rate of $17.1 \mathrm{kN} / \mathrm{min}$. The cube samples with the size of $50.8 \times 50.8 \times 50.8 \mathrm{~mm}(2$ in $\times 2$ in $\times 2$ in $)$ were cast. Three cubic specimens of each composition were prepared to measure the compressive strength.

Powder X-ray diffraction (XRD) carried out on a diffractometer (Rigaku, Tokyo, Japan) was employed to identify the crystalline phases of the $85^{\circ} \mathrm{C}$-cured sample. The samples were crushed, ground and passed through a 325 mesh screen. The scanning regions were between $2 \theta$ values of $3^{\circ}$ and $70^{\circ}$, at a resolution of $0.02^{\circ}$ / step.

For the water absorption test, the specimens were weighed $\left(W_{0}\right)$ after $200{ }^{\circ} \mathrm{C}$-heating, then the specimens were immersed in water at room temperature for $30 \mathrm{~min}$. After the immersion period, the specimens were taken out and wiped quickly with wet cloth, and then the mass was weighed $\left(W_{1}\right)$ [25]. The water absorption $\left(W_{A}\right)$ was calculated according to the formula:

$$
W_{A}=\frac{W_{1}-W_{0}}{W_{0}}
$$

To observe the self-degradation, the $200{ }^{\circ} \mathrm{C}$-heated specimens were placed into water at room temperature for $2 \mathrm{~h}$ (immersed in water for $2 \mathrm{~h}$ ) and $24 \mathrm{~h}$ (immersed in water for $24 \mathrm{~h}$ ). 
The compressive strength of samples immersed in water for different times was measured to assess the level of self-degradation.

The pieces of SDTSM with $2 \%$ PLA (after $85^{\circ} \mathrm{C}$-curing, $200^{\circ} \mathrm{C}$-heating, immersing in water for $2 \mathrm{~h}$ and for $24 \mathrm{~h}$ ) were stored in absolute alcohol to extract free water, and then dried at $60{ }^{\circ} \mathrm{C}$ for $6 \mathrm{~h}$. Then the pieces were examined by a scanning electron microscope (SEM, with an acceleration voltage of $15 \mathrm{kV}$; FEI, Hillsboro, OR, USA). In particular, the pieces of the samples after immersed in water for $2 \mathrm{~h}$ and $24 \mathrm{~h}$ were selected from the fractured surfaces of the degraded cement.

\section{Results and Discussion}

\subsection{Thermogravimetric Analysis (TGA)}

As the thermal properties of additives are important to the temporary sealing materials applied to geothermal wells, TGA and Py-GC/MS were employed to investigate the thermal properties of PLA. TGA curves tested in different atmospheres for non- and filtrate-treated PLA are shown in Figure 1. All of the TGA curves present only one stage of decomposition. The decomposition stage of original PLA in $\mathrm{N}_{2}$ is between $300^{\circ} \mathrm{C}$ and $390^{\circ} \mathrm{C}$, and PLA decomposes completely in this stage. Similarly, original PLA decomposes in the one decomposition stage at between $260{ }^{\circ} \mathrm{C}$ and $360^{\circ} \mathrm{C}$. The decomposition stage of the filtrate-treated PLA is between $200{ }^{\circ} \mathrm{C}$ and $335^{\circ} \mathrm{C}$ with the weight loss of $88.8 \%$, and $200 \sim 350{ }^{\circ} \mathrm{C}$ with the weight loss of $87.9 \%$, in $\mathrm{N}_{2}$ and in air, respectively. After being treated with the filtrate of SDTSM at room temperature for $72 \mathrm{~h}$ and at $85^{\circ} \mathrm{C}$ for $24 \mathrm{~h}$, the thermal decomposition temperature declined both in $\mathrm{N}_{2}$ and in air. The decomposition temperature drops from $300{ }^{\circ} \mathrm{C}$ to $200{ }^{\circ} \mathrm{C}$ in $\mathrm{N}_{2}$, and drops from $260{ }^{\circ} \mathrm{C}$ to $200{ }^{\circ} \mathrm{C}$ in air. The similar phenomenon was also reported by literature [26], which showed that with increasing time of the hydrolysis experiment, thermal stability of PLA decreased, as reflected by the changes in TGA curves. PLA hydrolyzes in acidic and basic solutions, especially at elevated temperature [26-28]. The $\mathrm{pH}$ value of filtrate of SDTSM without PLA is 13.16, alkalescence. The filtrate containing PLA powders was cured at $85^{\circ} \mathrm{C}$ to simulate the curing conditions of cement, resulting in the hydrolysis of PLA. The hydrolytic decomposition leads to a decrease in molecular weight $[26,27,29]$. The thermal stability of PLA is closely related to the molecular weight. Cam et al. [30] reported that the thermal decomposition temperature rose with the increase in the molecular weight. Therefore, PLA hydrolyzed in the $\mathrm{pH}$ 13.16 filtrate at $85^{\circ} \mathrm{C}$, leading to a decrease in molecular weight, and thus the thermal decomposition temperature declined.

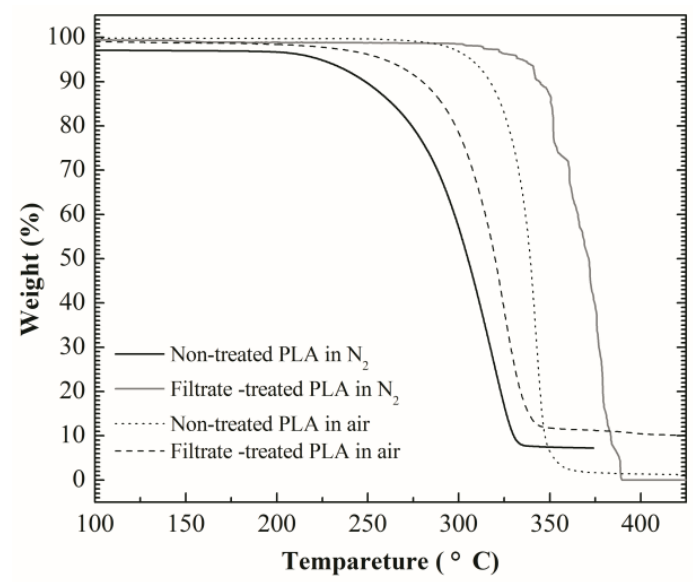

Figure 1. TGA curves for the non- and filtrate-treated PLA.

\subsection{Pyrolysis-Gas Chromatography/Mass Spectroscopy (Py-GC/MS)}

Figure 2 shows the Py-GC/MS abundance-retention time curve of non-treated PLA. Table 2 shows the main pyrolysis derivatives, of which peak area accounts for more than $1.5 \%$ of the total, along with 
their peak area \% of the total obtained from Py-GC/MS for non-treated PLA. The main pyrolysis derivatives are $\gamma$-butyrolactone, $o$-xylene, hexyl alcohol and 3-methylpent-1-en-3-ol. The boiling points of $o$-xylene, hexyl alcohol and 3-methylpent-1-en-3-ol are $144.4^{\circ} \mathrm{C}, 157.0^{\circ} \mathrm{C}$, and $115.9^{\circ} \mathrm{C}$, respectively. Although the boiling point of $\gamma$-butyrolactone is $204^{\circ} \mathrm{C}$, it evaporates together with water vapor [31]. When the environment temperature was above $100{ }^{\circ} \mathrm{C}$, water in cement turned into water vapor. When the cement was heated at $200^{\circ} \mathrm{C}, \gamma$-butyrolactone evaporated with water vapor. Thus all of the main products $\left(90.83 \%\right.$ of the total) were in gaseous state when the cement was heated at above $200{ }^{\circ} \mathrm{C}$. The large release of volatile derivatives emanated would enhance the magnitude of self-degradation of cement [4].

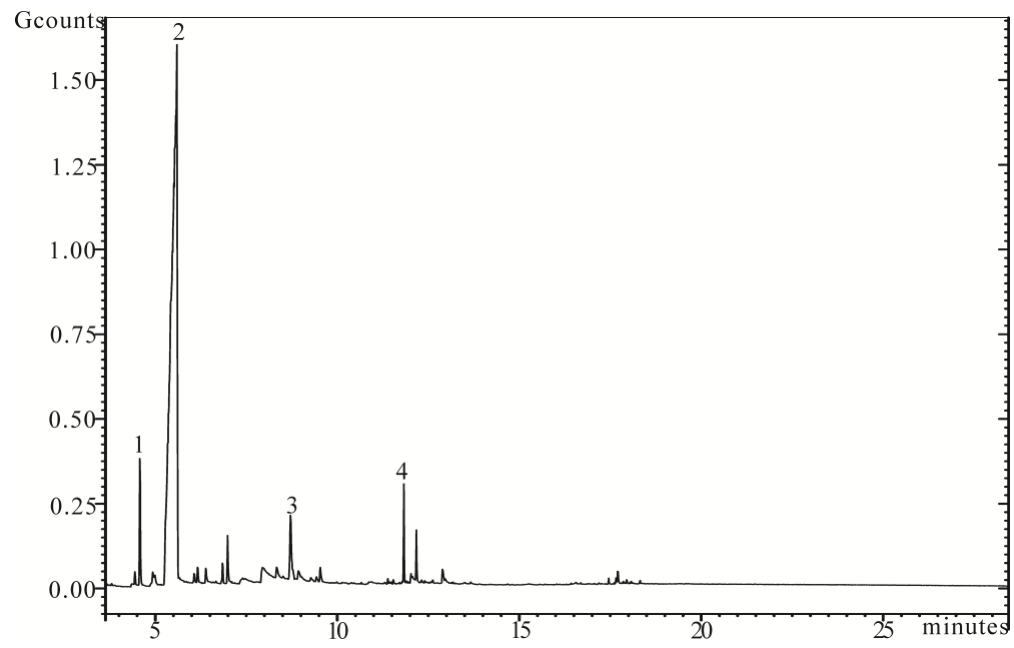

Figure 2. Py-GC/MS abundance-retention time curve of non-treated PLA.

Table 2. Main pyrolysis derivatives along with their peak area \% of total obtained from Py-GC/MS for non-treated PLA.

\begin{tabular}{cccc}
\hline Number & Retention Time (min) & Compounds & Peak Area \% of Total \\
\hline 1 & 4.577 & $o-X y l e n e$ & 3.29 \\
2 & 5.514 & $\gamma$-Butyrolactone & 82.91 \\
3 & 8.717 & Hexyl alcohol & 2.95 \\
4 & 11.829 & 3-Methylpent-1-en-3-ol & 1.68 \\
\hline
\end{tabular}

\subsection{Rheological Properties}

Fluidity, viscosity and shear stress can be used to describe the flow of cement pastes. As shown in Figure 3, the fluidities of the control and SDTSM without PLA are $17.7 \mathrm{~cm}$ and $16.2 \mathrm{~cm}$, indicating that CMC decreased the fluidity of cement. The enhancement in fluidity is $14.8 \%$ with the addition of $2 \%$ PLA, compared to SDTSM without PLA. The effect of PLA dosage on fluidity of SDTSM presents a fluctuation tendency. The additions of $2 \%$ and $8 \%$ PLA reach two different peak values of $18.6 \mathrm{~cm}$ and $18.3 \mathrm{~cm}$, respectively. Despite the fact that SDTSMs with $6 \%$ and 10\% PLA present lower fluidity, the values are higher than SDTSM without PLA, suggesting that PLA enhanced the fluidity. As shown in Table 3, the shear stress of all samples increases with the increasing shear rate. Shear stress-shear rate relationships were described according to Bingham plastic model [32]:

$$
\tau=\tau_{0}+\mu_{p} \gamma
$$

where $\tau$ is the shear stress $(\mathrm{Pa}), \mu_{p}$ is the plastic viscosity $(\mathrm{mPa} \cdot \mathrm{s}), \gamma$ is the shear rate $\left(\mathrm{s}^{-1}\right)$ (also referred to as the shear strain rate) and $\tau_{0}$ is the yield stress (Pa) (also referred to as the yield point). Linear fitting of rheological curves of the control and SDTSMs with $0 \%, 1 \%, 2 \%, 3 \%, 4 \%, 5 \%, 6 \%$, 
$7 \%, 8 \%, 9 \%$ and $10 \%$ PLA was performed by using a computer software named 'Origin', as shown in Figure 4 , to determine a slope (plastic viscosity) and an intercept (yield stress). The quality of the fitting of the experimental data to the Bingham plastic model was evaluated using error function assessments, namely, the coefficient of determination $\left(R^{2}\right)$ and residual root-mean-square errors (RMSE) tests. The values $R^{2}$ and RMSE are given by Equations (3) and (4), respectively:

$$
\begin{gathered}
R M S E=\sqrt{\frac{1}{n-p} \sum_{i=1}^{n}\left(q_{e i}-q_{c i}\right)^{2}} \\
R^{2}=\left(\frac{\sum_{i=1}^{n}\left(q_{e i}-\overline{q_{e}}\right)\left(q_{c i}-\overline{q_{c}}\right)}{\sqrt{\sum_{i=1}^{n}\left(q_{e i}-\overline{q_{e}}\right)^{2}} * \sqrt{\sum_{i=1}^{n}\left(q_{c i}-\overline{q_{c}}\right)^{2}}}\right)^{2}
\end{gathered}
$$

where $q_{e i}$ and $q_{c i}$ are the experimental and calculated shear stress, respectively; $\overline{q_{e}}$ and $\overline{q_{c}}$ are the mean of experimental and calculated shear stress values; $n$ is the number of experimental data points; and $p$ is the number of parameters in the model equation. The experimental data obeyed one model well when the $R^{2}$ value was close to 1 , and the RMSE value was close to zero.

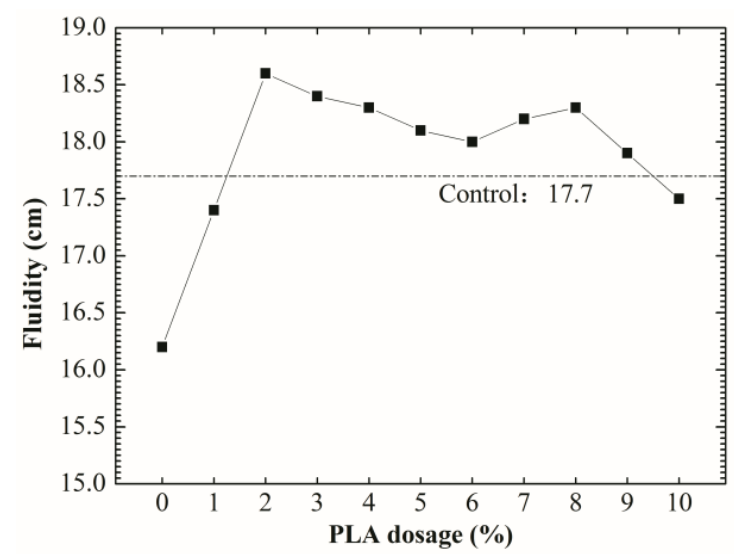

Figure 3. Fluidity of the slurries of the control and SDTSMs with different PLA dosages.

Table 3. The values of shear stress (Pa) of slurries of the control and SDTSMs with different PLA dosages at different shear rates.

\begin{tabular}{ccccc}
\hline \multirow{2}{*}{ PLA Dosage (\%) } & \multicolumn{4}{c}{ Shear Rates $\mathbf{( s}^{-\mathbf{1}}$ ) } \\
\cline { 2 - 5 } & $\mathbf{5 . 1 1}$ & $\mathbf{1 0 . 2 1}$ & $\mathbf{1 7 0}$ & $\mathbf{3 4 0}$ \\
\hline Control & 1.02 & 2.30 & 14.82 & 27.59 \\
0 & 5.37 & 7.67 & 62.85 & 123.92 \\
1 & 3.83 & 7.41 & 52.12 & 97.35 \\
2 & 3.32 & 5.37 & 42.41 & 76.65 \\
3 & 3.58 & 5.62 & 47.01 & 87.13 \\
4 & 4.34 & 6.64 & 53.14 & 98.37 \\
5 & 4.85 & 8.94 & 61.32 & 110.89 \\
6 & 5.11 & 7.41 & 62.09 & 114.98 \\
7 & 3.83 & 9.45 & 54.93 & 100.16 \\
8 & 4.34 & 5.62 & 41.39 & 76.14 \\
9 & 3.83 & 6.13 & 48.80 & 90.45 \\
10 & 4.85 & 6.64 & 58.51 & 109.35 \\
\hline
\end{tabular}

The values of $\mu_{p}, \tau_{0}$, the coefficient of determination $\left(R^{2}\right)$ and the residual root mean square error (RMSE) values are shown in Table 4. All of the values of $R^{2}$ are between 0.99 and 1 , and all of the RMSEs are smaller than 2.7 with the mean value of 1.4694, indicating that the relationship between shear stress and shear rate of all the cement pastes can be described by the Bingham plastic model. The plastic 
viscosity curve of SDTSMs with different PLA dosage is shown in Figure 5. Similar to the fluidity curve, the plastic viscosity curve also presents a fluctuation tendency as the PLA dosage increases. However, contrast to fluidity curve, two different minimum plastic viscosity values, $218.16 \mathrm{mPa} \cdot \mathrm{s}$ and $214.57 \mathrm{mPa} \cdot \mathrm{s}$ are obtained by adding $2 \%$ and $8 \%$ PLA, which decrease by $38.04 \%$ and $39.07 \%$ compared to that of SDTSM without PLA. Although the fluidity and plastic viscosity curves present fluctuation tendency, the addition of PLA increased the fluidity and reduced the plastic viscosity and yield stress compared to SDTSM without PLA, and thus improved the rheological properties of the CMC-modified cement. The fluidity is related to rheological parameters, viscosity and yield stress [33]. In general, the increment of rheological parameters is accompanied by a reduction of fluidity, and vice versa, as reported in literatures [34-36]. Assaad [34] reported that the extraction of water decreased the fluidity and increased the viscosity of inject cementitious grouts. Celik et al. [35] reported that increasing the replacement level of rice husk ash increased plastic and apparent viscosity, and the yield stress, but also decreased fluidity. Shang et al. [36] reported the addition of graphene oxide into the cement caused a noticeable reduction in fluidity and increased rheological parameters.

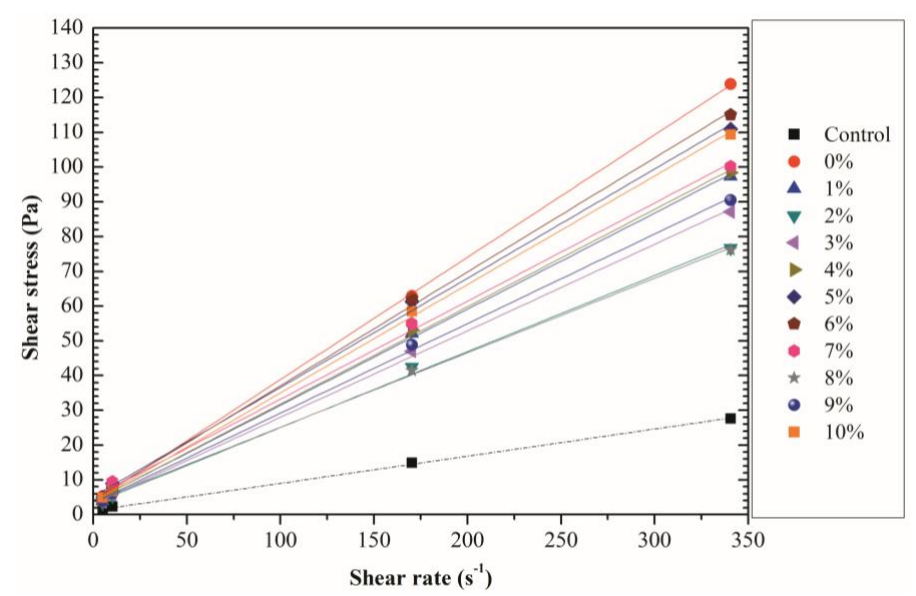

Figure 4. The rheological curves of the control and SDTSMs with different PLA dosages.

Table 4. The values of $\tau_{0}(\mathrm{~Pa}), \mu_{p}(\mathrm{mPa} \cdot \mathrm{s}), R^{2}$ and $R M S E$ of the control and SDTSMs with different PLA dosages.

\begin{tabular}{ccccc}
\hline PLA Dosage (\%) & $\boldsymbol{\tau}_{\mathbf{0}}$ & $\boldsymbol{\mu}_{\boldsymbol{p}}$ & $\boldsymbol{R}^{\mathbf{2}}$ & RMSE \\
\hline Control & 1.14954 & 78.17 & 0.99878 & 0.53179 \\
0 & 3.62560 & 352.13 & 0.99991 & 0.66444 \\
1 & 3.80992 & 276.44 & 0.99924 & 1.4894 \\
2 & 3.17759 & 218.16 & 0.99837 & 1.7229 \\
3 & 3.07989 & 248.97 & 0.99926 & 1.3228 \\
4 & 3.76898 & 280.15 & 0.99930 & 1.4440 \\
5 & 5.15655 & 314.27 & 0.99831 & 2.5178 \\
6 & 4.25199 & 327.94 & 0.99931 & 1.6738 \\
7 & 4.94911 & 282.35 & 0.99774 & 2.6160 \\
8 & 3.64514 & 214.57 & 0.99943 & 1.0007 \\
9 & 3.38908 & 257.79 & 0.99893 & 1.3432 \\
10 & 3.75633 & 312.99 & 0.99931 & 1.3058 \\
\hline
\end{tabular}

The powders of PLA, slag and fly ash were screened by sieves with different pore diameters to investigate the influences of PLA powders on the rheological properties of cement slurries. The weight percentages of powders between different pore diameters sieves are provided in Table 5, from which we can learn that the PLA particles are larger than those of slag and fly ash. The increased dosage of the large particle PLA powders changed the particle size distribution, and thus changed the specific surface area and particle number density, both of which have effects on the rheological behavior of cementitious slurries, as reported in [37,38]. Bentz et al. [37] reported that, as the fly ash particles were 
larger than the cement particles, the replacement of fly ash decreased the particle number density of cement-fly ash pastes and produced significantly lower yield stress values. Vance et al. [38] reported that the yield stress and plastic viscosity of the cement pastes containing limestone powder were found to increase with the specific surface area. Besides, as the cement was prepared through adding water by the water/dry pozzolana cement ratio of constant 0.6 , the addition of PLA enhanced solid content in the cement slurry. The increased solid content increases the viscosity and yield stress and decreases the fluidity. Therefore, the fluidity and plastic viscosity curves present a fluctuation tendency resulting from the combined influences of particle size distribution and the solid content change as the PLA dosage is increased.

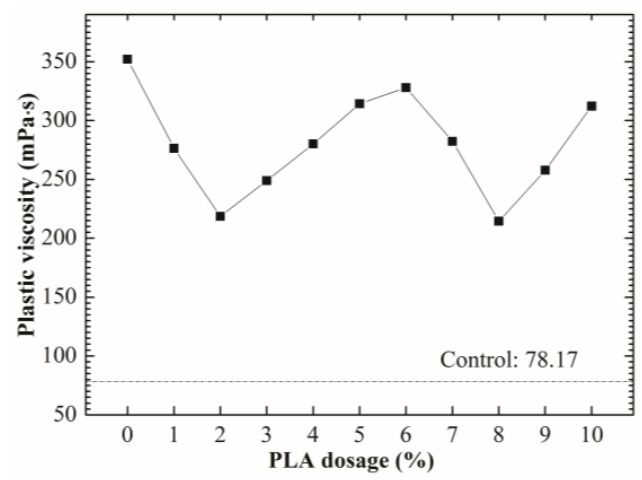

Figure 5. The plastic viscosity of the control and SDTSMs with different PLA dosages.

Table 5. The weight percent of powders between different pore diameters sieves of PLA, slag and fly ash.

\begin{tabular}{cccc}
\hline Pore Diameter $(\mu \mathrm{m})$ & PLA & Slag & Fly Ash \\
\hline$>550$ & 0.0903 & 0 & 0 \\
$550 \sim 325$ & 25.67676 & 0 & 0 \\
$325 \sim 250$ & 60.11703 & 0 & 0 \\
$250 \sim 120$ & 12.70065 & 53.76577 & 0.56842 \\
$120 \sim 106$ & 1.04332 & 11.69448 & 6.977688 \\
$<106$ & 0.371942 & 34.53976 & 92.45389 \\
\hline
\end{tabular}

\subsection{Compressive Strength of $85^{\circ} \mathrm{C}$-Cured Specimens}

Figure 6 shows the compressive strength of the $85{ }^{\circ} \mathrm{C}$-cured samples of the control and SDTSMs with different PLA dosages. The compressive strength of SDTSMs without PLA exhibits an enhancement of $29.90 \%$ compared to the control, indicating that CMC has an ability to increase the compressive strength of the alkali-activated slag/Class $\mathrm{C}$ fly ash cement. The reduction in compressive strength is $9.8 \%, 32.8 \%$ and $54.8 \%$ with the addition $2 \%, 4 \%$ and $6 \%$ PLA compared to SDTSM without PLA, respectively, revealing that PLA decreased the compressive strength of $85{ }^{\circ} \mathrm{C}$-cured SDTSM. However, SDTSM with $2 \%$ PLA exhibits an enhancement in compressive strength compared to the control, indicating that $1 \%$ CMC with a lesser PLA dosage could still reinforce the compressive strength of the sodium silicate-activated slag/Class C fly ash cement. The compressive strength of SDTSM decreased as the PLA dosage increased, may result from the hydrolysis of ester bonds in PLA yielding- $\mathrm{COOH}$ groups, which reacted with $\mathrm{OH}^{-}$, leading to a decrease in alkali content. The dosage of the alkali activator has notable influence on the strengths of cement. Abdalqader et al. [39] reported that increasing the activator dosage led to an increase in the strengths of sodium carbonate activated slag/fly ash cement at all ages. Therefore, the SDTSM containing a larger PLA dosage presented a lower $85^{\circ} \mathrm{C}$-cured compressive strength. The accepted compressive strength for the drilling operations to resume after curing circulation losses is $3.5 \mathrm{MPa}$ [4], so even the compressive strength of SDTSM with $8 \%$ PLA is more than sufficient for plugging fractures and resuming drilling. 


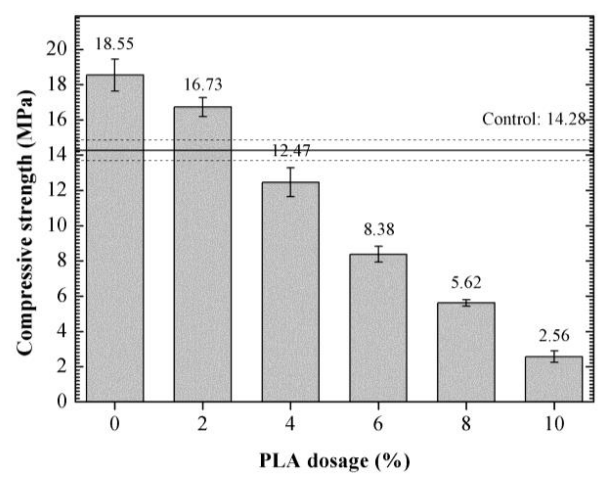

Figure 6. Compressive strength of $85^{\circ} \mathrm{C}$-cured specimens of the control and SDTSMs with different PLA dosages.

\subsection{Powder X-ray Diffraction (XRD)}

All of the XRD patterns of the $85{ }^{\circ} \mathrm{C}$-cured samples (shown in Figure 7) exhibit a crystalline phase at about $2 \theta$ value of $26.6^{\circ}$, which indicates the presence of quartz attributed to the Class $C$ fly ash residue. Besides, each XRD pattern exhibits an amorphous hump between $2 \theta$ values of $20^{\circ}$ and $40^{\circ}$ due to the non-hydrated slag. The diffuse peak at about $2 \theta$ value of $29.5^{\circ}$ is assigned to calcium-silicate-hydrate (C-S-H) phase or calcite [40,41]. The XRD patterns of the $85^{\circ} \mathrm{C}$-cured samples seem to be similar to each other, the diffraction peaks are in the same positions, revealing that the effect of PLA or CMC on the types of hydrate products of the alkali activated slag/Class C fly ash cement is less pronounced. However, the intensity value of the peak at $29.5^{\circ}$ of the control and SDTSM with $0 \%, 2 \%, 4 \%, 6 \%, 8 \%$ and $10 \%$ PLA is $170,170,170,161,153,150$ and 137 , in sequence. The intensity is closely associated with crystalline phases, as reported in literatures [42-44]. Literature [42] reported that the intensity of quartz and mullite peaks was decreased related to the higher reactivity of fly ash which resulted into consumption of quartz and mullite phase. Literature [43] reported that the increasing intensity of cementitious product peak indicated the increase in the cementitious compounds. Literature [44] reported that the intensity of calcium hydroxide peak decreased due to a rapid consumption of $\mathrm{Ca}(\mathrm{OH})_{2}$. In addition, the peak area is 3103, 2564, 2457, 2342, 2024, 1371 and 1300, respectively; and the sharpness of the peak weakens with the increasing PLA dosage, compared to SDTSM without PLA. To some extent, a sharper peak means a better crystallinity, and a larger peak area reflects a larger amount of the crystalline phase. Literature [45] reported that the broad crystallization peak indicated surface crystallization whereas the sharp peak signified bulk crystallization. Therefore, the intensity, peak area and sharpness of peak at $29.5^{\circ}$ decrease as the increasing PLA dosage suggesting that the hydrate products decreases with the increasing PLA dosage. Furthermore, the decrease of hydrate products attributed to the compressive strength decrease of the $85^{\circ} \mathrm{C}$-cured cement.

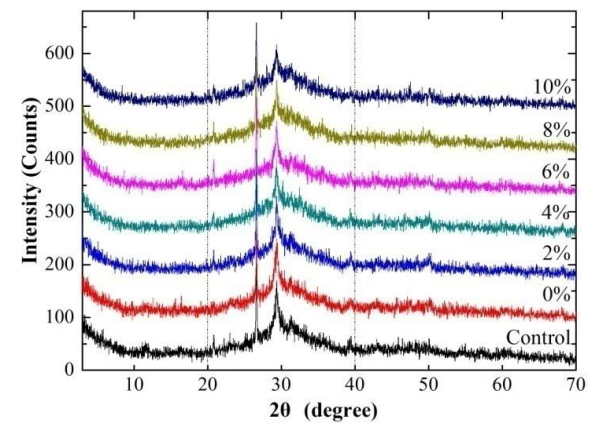

Figure 7. XRD patterns of $85{ }^{\circ} \mathrm{C}$-cured specimens of the control and SDTSMs with different PLA dosages. 


\subsection{Water Absorption}

Figure 8 shows the water absorption of the $200{ }^{\circ} \mathrm{C}$-heated specimens of the control and SDTSMs with different PLA dosages. The value of SDTSM with $0 \%, 2 \%, 4 \%, 6 \%, 8 \%$ and $10 \%$ PLA is $19.5 \%$, $24.4 \%, 27.1 \%, 31.7 \%, 34.2 \%$ and $37.5 \%$. The water absorption increased by $92.49 \%$ due to the addition of $10 \%$ PLA. The water absorption was increased with the increasing PLA dosage, suggesting that the addition of PLA contributed to the rapid entering of water into the specimens in a short time. Additionally, larger water absorption is usually accompanied by a larger porosity and a looser structure. Aprianti et al. [46] reported that a denser cement mortar microstructure achieved a higher compressive strength with lower water absorption. Hossain et al. [47] reported that the incorporation of soluble silicates into alkali-activated blast furnace slag paste led to a denser and more homogeneous microstructure with lower water absorption and apparent porosity. Therefore, the enhancement in water absorption due to the addition of PLA, points to a larger porosity and a looser structure, to some extent.

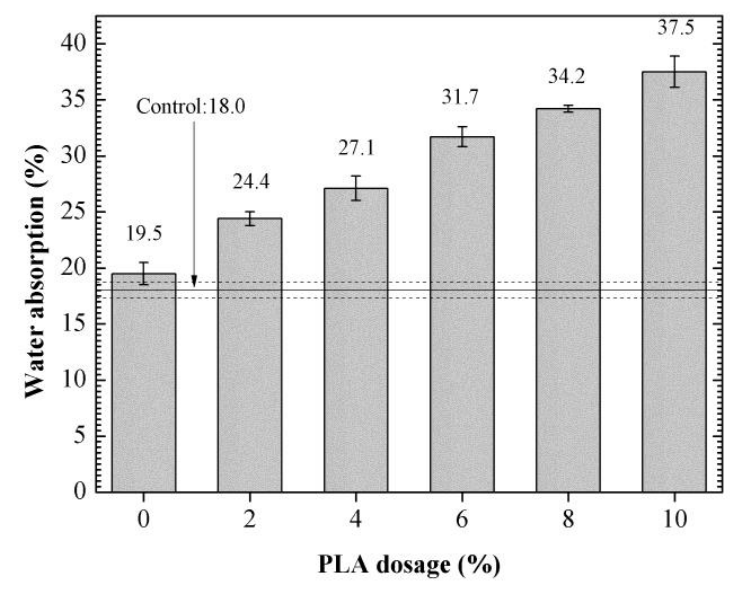

Figure 8. Water absorption of the $200{ }^{\circ} \mathrm{C}$-heated specimens of control and SDTSMs with different PLA dosages.

\subsection{Self-Degradation}

To observe the self-degradation, the $200^{\circ} \mathrm{C}$-heated samples of SDTSM were immersed in water for $2 \mathrm{~h}$ and $24 \mathrm{~h}$. Then the water-immersed specimens were cut into pieces and observed under a polarizing microscope and SEM. The compressive strength of the samples immersed in water for different times was measured to assess the level of degradation.

Figure 9 shows the images of section of $200^{\circ} \mathrm{C}$-heated samples after immersed in water for $2 \mathrm{~h}$. The amount of pores in SDTSM increases with the increasing PLA dosage. Figure 10 shows the images of the section of the $200{ }^{\circ} \mathrm{C}$-heated samples after immersed in water for $24 \mathrm{~h}$. The images illustrate that after the immersing period for $24 \mathrm{~h}$, cracks appeared in SDTSM specimens, compared to the specimens immersed for $2 \mathrm{~h}$, indicating that the self-degradation level of cement increased with the extension of immersing-time. However, contrary to SDTSMs with PLA, the specimens of the control are dense, no matter immersed in water for $2 \mathrm{~h}$ or for $24 \mathrm{~h}$.

Figure 11 shows the compressive strength of the control and SDTSMs with different PLA dosages after $200{ }^{\circ} \mathrm{C}$-heated, immersed in water for $2 \mathrm{~h}$ and $24 \mathrm{~h}$. All of the samples show declines in compressive strength after different immersing periods compared to the $200{ }^{\circ} \mathrm{C}$-heated. SDTSM without PLA presents a reduction in compressive strength of $15.14 \%$ and $24.77 \%$ compared to the $200{ }^{\circ} \mathrm{C}$-heated specimens, after immersed in water for $2 \mathrm{~h}$ and $24 \mathrm{~h}$, respectively. The reduction of SDTSMs with $2 \%$ PLA is $35.75 \%$ and $56.73 \%$, respectively. The reduction extent of cement immersed in water for $2 \mathrm{~h}$ and $24 \mathrm{~h}$ increased as the addition of PLA, revealing that PLA promoted the self-degradation of SDTSM. 


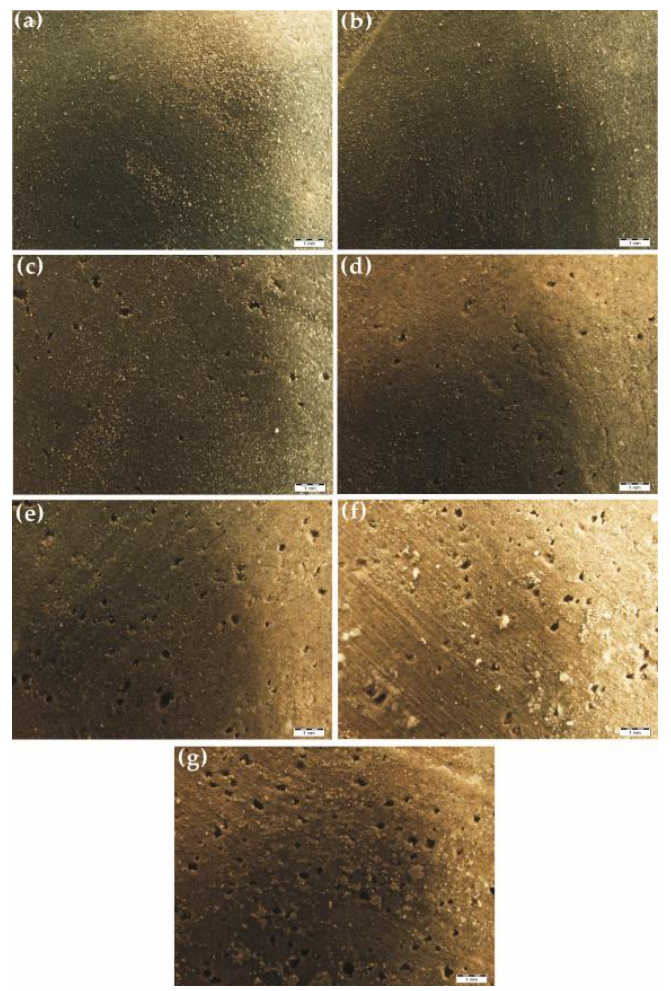

Figure 9. Images of the section of $200{ }^{\circ} \mathrm{C}$-heated samples of the control and SDTSMs with different PLA dosages after immersed in water for 2 h: (a) the control; (b) $0 \%$; (c) $2 \%$; (d) $4 \%$; (e) $6 \%$; (f) $8 \%$; (g) $10 \%$.

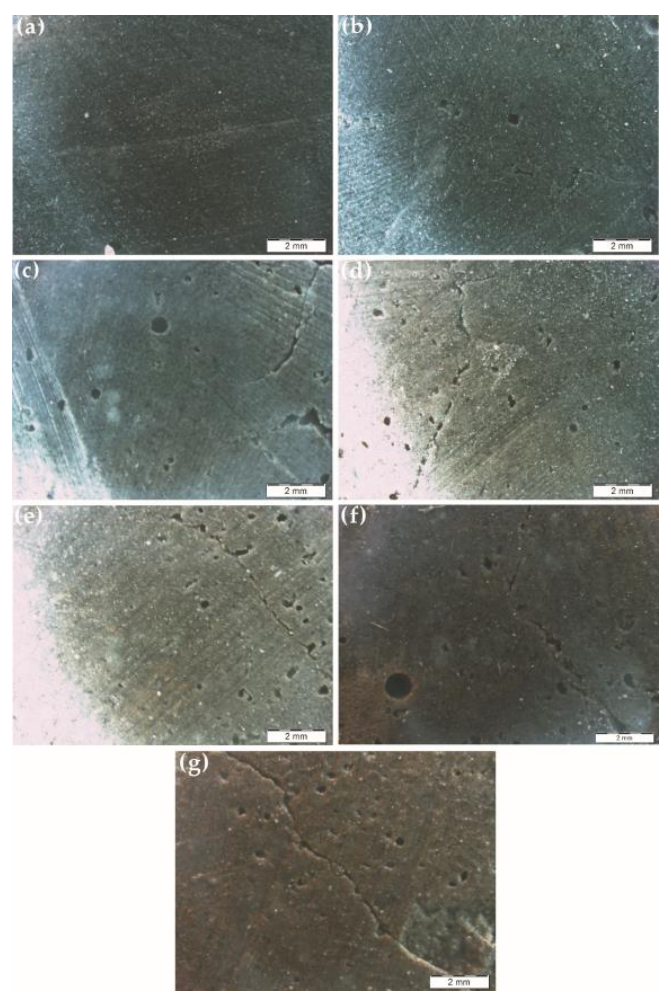

Figure 10. Images of the section of the $200{ }^{\circ} \mathrm{C}$-heated samples after being immersed in water for $24 \mathrm{~h}$ : (a) the image of the control; (b) $0 \%$; (c) $2 \%$; (d) $4 \%$; (e) $6 \%$; (f) $8 \%$; (g) $10 \%$. 


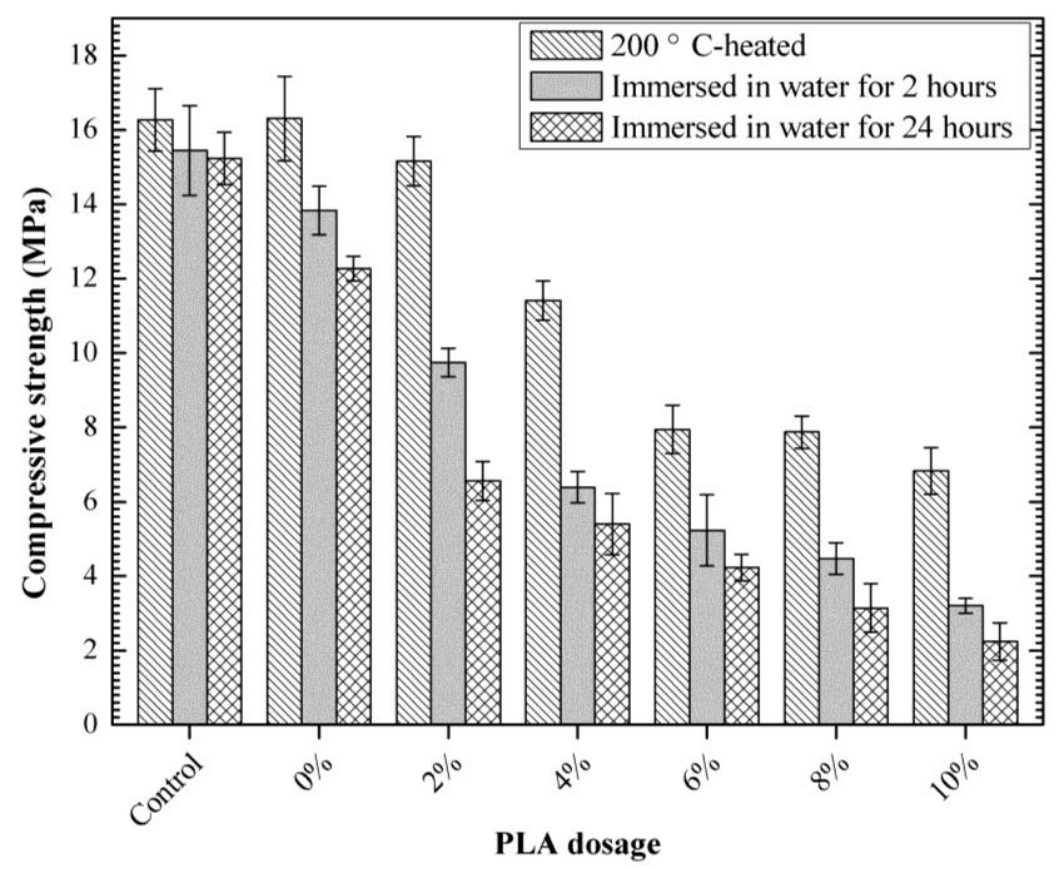

Figure 11. Compressive strength of control and SDTSM with different PLA dosages after being $200{ }^{\circ} \mathrm{C}$-heated, immersed in water for $2 \mathrm{~h}$ and $24 \mathrm{~h}$.

With the addition of $2 \%$ and $8 \%$ PLA, SDTSM showed lower viscosity and larger fluidity. However, increasing the PLA dosage decreased the compressive strength of the $85^{\circ} \mathrm{C}$-cured cement. The compressive strength of $85^{\circ} \mathrm{C}$-cured cement should be kept high enough to plug fractures and resume drilling operation. In addition, the compressive strength of $200{ }^{\circ} \mathrm{C}$-heated SDTSM with $2 \%$ PLA immersed in water for $24 \mathrm{~h}$ decreased by $56.73 \%$, when compared to the $200{ }^{\circ} \mathrm{C}$-heated specimen, suggesting the significant effect of $2 \%$ PLA on the self-degradation of SDTSM. Therefore the optimum dosage of PLA is $2 \%$, which can make the cement self-degrade to disintegrate for production, and obtain a larger $85^{\circ} \mathrm{C}$-cured compressive strength to resume drilling.

\subsection{Self-Degradation Mechanism}

As shown in Figure 12a, the PLA particles distribute in the cement, after $85^{\circ} \mathrm{C}$-curing, besides, there are some pores as the particles were peeled off the SEM samples during the preparation. However, these particles can't be observed in Figure $12 \mathrm{~b}-\mathrm{d}$, after the $200^{\circ} \mathrm{C}$-heating. As the melting temperature of PLA is $155 \sim 165^{\circ} \mathrm{C}$ (as shown in Table 1), it melted during the period of $200^{\circ} \mathrm{C}$-heating. Meanwhile, the thermal decomposition of PLA produced $\gamma$-butyrolactone, $o$-xylene, hexyl alcohol and 3-methylpent-1-en-3-ol, all of which are in gaseous states, when the temperature was above $200{ }^{\circ} \mathrm{C}$, thus created a large amount of pores in cement. The amount of the pores increases as the increase of PLA dosage, as shown in Figures 9 and 10. Since the volume of water added in to cement was constant when preparing the samples, the pores attributed to the evaporation of the water is constant. The significant increase of the amount of the pores resulted from the PLA dosage increased. 

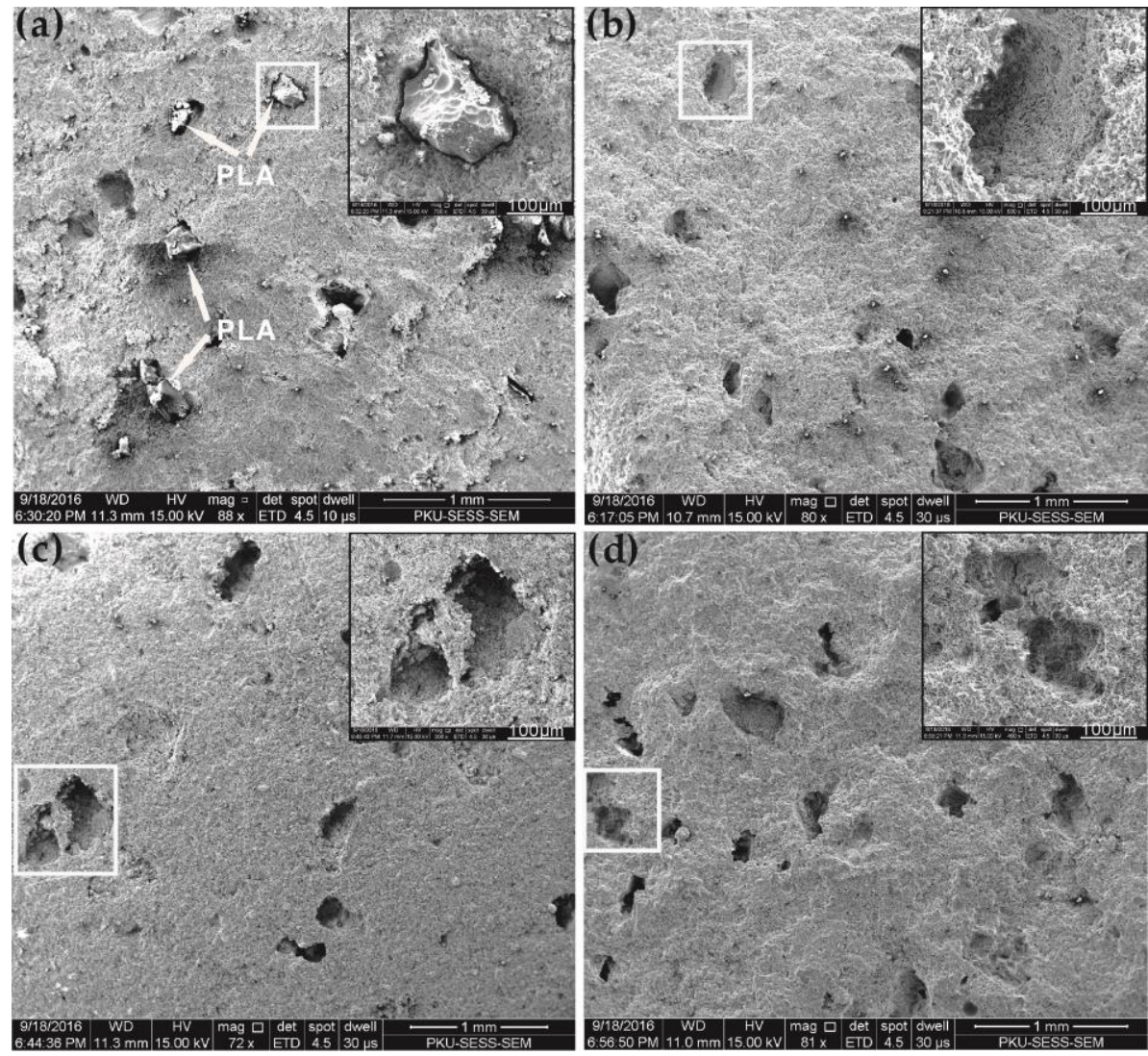

Figure 12. SEM images of smaller magnification of the SDTSM with $2 \%$ PLA after different periods:

(a) $85^{\circ} \mathrm{C}$-cured; (b) $200^{\circ} \mathrm{C}$-heated; (c) immersed in water for $2 \mathrm{~h}$ and (d) immersed in water for $24 \mathrm{~h}$.

High strength is related to a compact microstructure, therefore, a loose microstructure results in decreasing mechanical properties. The fact that porosity has significant effects on the cement strength has been reported in many references. Habib et al. [48] found that increasing dosages of melamine formaldehyde sulfanilate and cyclohexanone formaldehyde sulfonate led to a decrease in the total porosity of the resulting cement pastes, and consequently the compressive strength value increased. Zhang et al. [49] reported that the compressive strength of alkali-activated cement decrease was almost linear with the increasing total porosity at the studied range. Huang et al. [50] reported that the strength loss of limestone powder-incorporated mortar increased in comparison with Portland cement mortar, as a result of an increase in porosity. Norambuena-Contreras et al. [51] reported that the carbon powder waste increased the effective macroporosity of the cement paste, and weakened the microstructure, thus presented a lower strength resistance. The phenomenon that the compressive strength of $200{ }^{\circ} \mathrm{C}$-heated SDTSM decreases as the PLA dosage increases, since PLA created a large amount of pores when compared with the SDTSM without PLA, supporting the point that porosity makes significant effects on the cement strength.

The greater magnification SEM images of the border of PLA particles and cementitious material (a), the surfaces of the pores in the samples after heated (b) and immersed in water (c), (d), are shown in Figure 13. The microstructures of the cementitious material in (a) and (b) are observed more compact than in (c) and (d), especially than in (d) which has internal micro-cracks. The microstructures of samples which were immersed in water are looser than those non-immersed. Sugama [4] pointed out that the dissolution of abundant $\mathrm{CMC}$ and sodium silicate reaction products generated in situ heat in CMC modified sodium silicate-activated slag/Class C fly ash cement, when contacted with water. The high heat release was considered to play a pivotal role in the self-degradation performance of alkali-activated slag/Class C fly ash blend cement. 


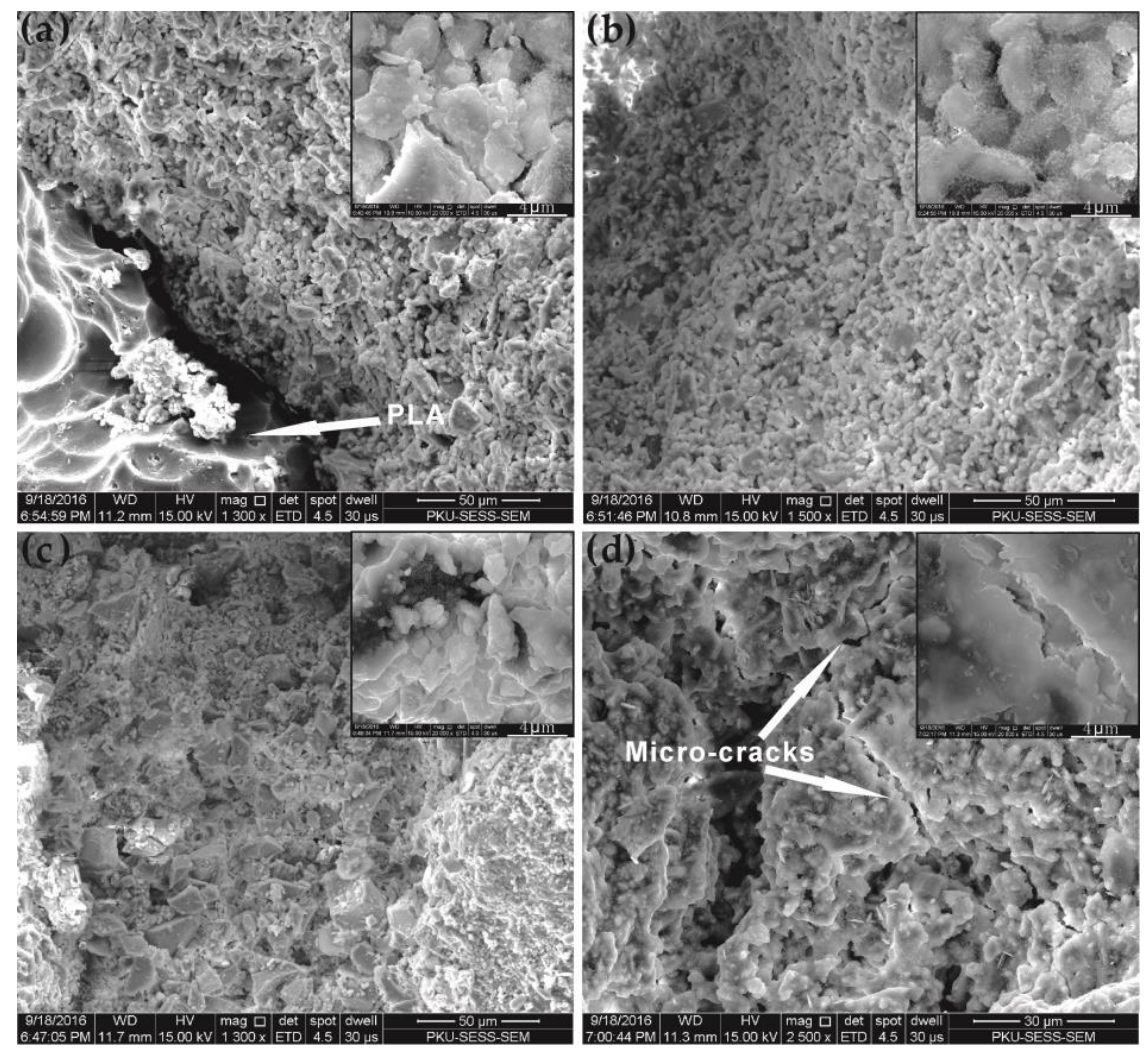

Figure 13. SEM images of greater magnification of the SDTSM with $2 \%$ PLA after different periods: (a) $85^{\circ} \mathrm{C}$-cured; (b) $200{ }^{\circ} \mathrm{C}$-heated; (c) immersed in water for $2 \mathrm{~h}$ and (d) immersed in water for $24 \mathrm{~h}$.

Besides, some other components in cement are dissolved in water when the cement is in contact with water after $200^{\circ} \mathrm{C}$-heating. We believe that this dissolution process itself should also contribute to the cement degradation. The dissolution process may lead to a chemical deterioration, which destroys the microstructures of the cement. References [52-54] reported that pure water or ion solutions leads to leaching of calcium from cement-based materials. Calcium leaching has a strong impact on their microstructure because of the dissolution of hydrated phases, and reduces the cement strength by perforating a highly eroded microstructure.

In addition, the many more pores generated by PLA made the water impregnate into cement more easily (shown in Figure 8), which made the dissolution progress faster, and then destroyed the cement microstructure, thus facilitating cement degradation. The dissolution continued as the time was extended, with the destruction of cement microstructure, as reflected by the continuous decrease of the compressive strength.

\section{Conclusions}

This paper was aimed at studying the potential of PLA for improving the fluidity and further promoting the self-degradation of SDTSM for geothermal wells, and the effect of PLA on the SDTSM performance. The conclusions obtained in this paper are as follows:

(1) The thermal decomposition temperature of PLA declined after treatment with filtrate of SDTSM. The main pyrolysis products of PLA are $\gamma$-butyrolactone, $o$-xylene, hexyl alcohol and 3-methylpent-1-en-3-ol.

(2) The optimum PLA dosage is $2 \%$. The addition of PLA increased the fluidity and reduced the viscosity of SDTSM, thus improving its rheological and pumping properties. $2 \%$ PLA enhanced the level of self-degradation, and ensured the SDTSM obtain a relatively larger $85^{\circ} \mathrm{C}$ compressive strength to resume drilling. 
(3) PLA or CMC have a small effect on the types of hydrated products of the $85^{\circ} \mathrm{C}$-cured alkali activated slag/Class $\mathrm{C}$ fly ash cement, however, the hydrated products decrease as the dosage of PLA increases.

(4) The existence of the large amount of pores generated by melting and thermal decomposition is the major reason for PLA enhancement of the self-degradation level of SDTSM. This works in two ways: first, the large amount of pores leads to a looser microstructure which results in lower strength; second, these pores make the water impregnate the cement more easily, and this made the dissolution progress faster to generate heat and destroy the microstructure of the cement, ultimately, facilitating the self-degradation.

As future work, considering that PLA decreased the compressive strength of $85^{\circ} \mathrm{C}$-cured SDTSM, we will try to enhance the strength by replacing PLA powders with fiber or increasing the dosage of sodium silicate. Besides, the rheological behaviors of SDTSMs should be investigated more deeply.

Acknowledgments: The presented data are the result of the project supported by National Natural Science Foundation of China (Grant No. 41572361) of "Design and Preparation of Green Environmental Friendly of Self-degradable Foamed Temporary Cementitious Sealing Materials for Geothermal Reservoir".

Author Contributions: The contributions of each author are as follows: Huijing Tan performed the main experiments, analyzed the experimental results and wrote the manuscript. Xiuhua Zheng conceived and designed the experiments, provided guidance and reviewed the manuscript. Chenyang Duan analyzed partial experimental results. Bairu Xia supervised the research throughout the whole process, reviewed the paper and gave advices about this manuscript. All authors have read and approved the final manuscript.

Conflicts of Interest: The authors declare no conflict of interest.

\section{References}

1. Olasolo, P.; Juarez, M.C.; Morales, M.P.; D'Amico, S.; Liarte, I.A. Enhanced geothermal systems (EGS): A review. Renew. Sustain. Energy Rev. 2016, 56, 133-144. [CrossRef]

2. Preisig, G.; Eberhardt, E.; Gischig, V.; Roche, V.; Van der Baan, M.; Valley, B.; Kaiser, P.K.; Duff, D.; Lowther, R. Development of connected permeability in massive crystalline rocks through hydraulic fracture propagation and shearing accompanying fluid injection. Geofluids 2015, 15, 321-337. [CrossRef]

3. Zhang, Y.; Guo, L.; Li, Z.; Yu, Z.; Xu, T.; Lan, C. Electricity generation and heating potential from enhanced geothermal system in Songliao Basin, China: Different reservoir stimulation strategies for tight rock and naturally fractured formations. Energy 2015, 93, 1860-1885. [CrossRef]

4. Sugama, T.; Pyatina, T. Effect of sodium carboxymethyl celluloses on water-catalyzed self-degradation of $200{ }^{\circ} \mathrm{C}$-heated alkali-activated cement. Cem. Concr. Compos. 2015, 55, 281-289. [CrossRef]

5. Sugama, T.; Butcher, T.; Brothers, L. Temporary Cementitious Sealing Materials. In Proceedings of the Geothermal Resources Council 2011 Annual Meeting, San Diego, CA, USA, 23-26 October 2011.

6. Li, F.Y. Experiments Research on Self-Degradable Slag/Fly Ash Cement for EGS Geothermal Wells. Master's Thesis, China University of Geosciences (Beijing), Beijing, China, 2015.

7. Gao, X.; Xu, Q.L.; Brouwers, H.J.H. Characterization of alkali activated slag-fly ash blends containing nano-silica. Constr. Build. Mater. 2015, 98, 397-406. [CrossRef]

8. Puertas, F.; Fernández-Jiménez, A. Mineralogical and microstructural characterisation of alkali-activated fly ash/slag pastes. Cem. Concr. Compos. 2003, 25, 287-292. [CrossRef]

9. Kastner, U.; Hoffmann, H.; Donges, R.; Hilbig, J. Structure and solution properties of sodium carboxymethyl cellulose. Colloids Surf. 1997, 123, 307-328. [CrossRef]

10. Akther, S.; Hwang, J.; Lee, H. Sedimentation characteristics of two commercial bentonites in aqueous suspensions. Clay Miner. 2008, 43, 449-457. [CrossRef]

11. Vipulanandan, C.; Mohammed, A. Smart cement rheological and piezoresistive behavior for oil well applications. J. Petrol. Sci. Eng. 2015, 135, 50-58. [CrossRef]

12. Feng, S.Q.; Zhang, N.W.; Ren, J. Thermal Degradation and Stability of Poly Lactic Acid. Plastics 2011, 40, 59-62. 
13. Habraken, W.J.E.M.; Liao, H.B.; Zhang, Z.; Wolke, J.G.C.; Grijpma, D.W.; Mikos, A.G.; Feijen, J.; Jansen, J.A. In vivo degradation of calcium phosphate cement incorporated into biodegradable microspheres. Acta Biomater. 2010, 6, 2200-2211. [CrossRef] [PubMed]

14. Zuo, Y.; Yang, F.; Wolke, J.G.C.; Li, Y.; Jansen, J.A. Incorporation of biodegradable electrospun fibers into calcium phosphate cement for bone regeneration. Acta Biomater. 2010, 6, 1238-1247. [CrossRef] [PubMed]

15. Krueger, R.; Seitz, J.; Ewald, A.; Bach, F.; Groll, J. Strong and tough magnesium wire reinforced phosphate cement composites for load-bearing bone replacement. J. Mech. Behav. Biomed. Mater. 2013, 20, 36-44. [CrossRef] [PubMed]

16. Dharmalingam, S.; Hayes, D.G.; Wadsworth, L.C.; Dunlap, R.N.; DeBruyn, J.M.; Lee, J.; Wszelaki, A.L. Soil Degradation of Polylactic Acid/Polyhydroxyalkanoate-Based Nonwoven Mulches. J. Polym. Environ. 2015, 23, 302-315. [CrossRef]

17. Ingrao, C.; Tricase, C.; Cholewa-Wojcik, A.; Kawecka, A.; Rana, R.; Siracusa, V. Polylactic acid trays for fresh-food packaging: A Carbon Footprint assessment. Sci. Total Environ. 2015, 537, 385-398. [CrossRef] [PubMed]

18. Halliburton Energy Services Inc. Re-Fracturing a Fracture Stimulated Subterranean Formation. Patent WO2,015,105,488 (A1), 9 January 2014.

19. Liang, F.; Reddy, B.R.; Nguyen, P.D. Tailoring Thermal, Mechanical, and Physical Properties of Degradable Polymers for Downhole Applications. In Proceedings of the 2014 AADE Fluids Technical Conference and Exhibition, Houston, TX, USA, 15-16 April 2014.

20. Halliburton Energy Services Inc. Wellbore Servicing Materials and Methods of Making and Using Same. Patent US8714249B1, 6 May 2014.

21. General Administration of Quality Supervision; Inspection and Quarantine of the People's Republic of China; Standardization Administration of the People's Republic of China. Method for Testing Uniformity of Concrete Admixture, 2nd ed.; Standards Press of China: Beijing, China, 2012; pp. 15-16.

22. American Petroleum Institute. Recommended Practice for Testing Well Cements, 2nd ed.; API Publishing Services: Washington, DC, USA, 2013; pp. 59-65.

23. General Administration of Quality Supervision; Inspection and Quarantine of the People's Republic of China. Standardization Administration of the People's Republic of China, Oil Well Cement, 3rd ed.; Standards Press of China: Beijing, China, 2005; pp. 13-16.

24. National Energy Administration. Performance Requirements for Oil Well Cement Slurries, 2nd ed.; Petroleum Industry Press: Beijing, China, 2010; pp. 1-3.

25. Hakamy, A.; Shaikh, F.U.A.; Low, I.M. Characteristics of nanoclay and calcined nanoclay-cement nanocomposites. Comp. B Eng. 2015, 78, 174-184. [CrossRef]

26. Olewnik-Kruszkowska, E. Influence of the type of buffer solution on thermal and structural properties of polylactide-based composites. Polym. Degrad. Stab. 2016, 129, 87-95. [CrossRef]

27. Stloukal, P.; Kalendova, A.; Mattausch, H.; Laske, S.; Holzer, C.; Koutny, M. The influence of a hydrolysis-inhibiting additive on the degradation and biodegradation of PLA and its nanocomposites. Polym. Test. 2015, 41, 124-132. [CrossRef]

28. Zhang, M.; Cui, C.N.; Song, J.; Qiu, J.H. Analysis of the Factors Influencing Degradability and Degradation Mechanism of Polylactic Acid. Pack Eng. 2008, 29, 16-19.

29. Zhang, X.; Espiritu, M.; Bilyk, A.; Kurniawan, L. Morphological behavior of poly (lactic acid) during hydrolytic degradation. Polym. Degrad. Stab. 2008, 93, 1964-1970. [CrossRef]

30. Cam, D.; Marucci, M. Influence of residual monomers and metals on poly (L-lactide) thermal stability. Polymer 1997, 38, 1879-1884. [CrossRef]

31. Zhang, S.G. Handbook of the Practical Fine Chemicals, 2nd ed.; Chemical Industry Press: Beijing, China, 1996; p. 513.

32. Zhang, Z.L.; Sui, T.B.; Chen, F.Y.; Wen, S.J.; Shi, H.X.; Wang, J.; Fan, L. Determined therheological properties of HBC cement paste slurry using rotational viscometer. Liaoning Build. Mater. 2005, 1, 18-20.

33. Domone, P.; HsiWen, C. Testing of binders for high performance concrete. Cem. Concr. Res. 1997, 27, 1141-1147. [CrossRef]

34. Assaad, J.J. Correlating water extraction to viscosity variations of injection grouts. Constr. Build. Mater. 2015, 77, 74-82. [CrossRef] 
35. Celik, F.; Canakci, H. An investigation of rheological properties of cement-based grout mixed with rice husk ash (RHA). Constr. Build. Mater. 2015, 91, 187-194. [CrossRef]

36. Shang, Y.; Zhang, D.; Yang, C.; Liu, Y.Y.; Liu, Y. Effect of graphene oxide on the rheological properties of cement pastes. Constr. Build. Mater. 2015, 96, 20-28. [CrossRef]

37. Bentz, D.P.; Ferraris, C.F.; Galler, M.A.; Hansen, A.S.; Guynn, J.M. Influence of particle size distributions on yield stress and viscosity of cement-fly ash pastes. Cem. Concr. Res. 2012, 42, 404-409. [CrossRef]

38. Vance, K.; Kumar, A.; Sant, G.; Neithalath, N. The rheological properties of ternary binders containing Portland cement, limestone, and metakaolin or fly ash. Cem. Concr. Res. 2013, 52, 196-207. [CrossRef]

39. Abdalqader, A.F.; Jin, F.; Al-Tabbaa, A. Development of greener alkali-activated cement: Utilisation of sodium carbonate for activating slag and fly ash mixtures. J. Clean. Prod. 2016, 113, 66-75. [CrossRef]

40. Abdalqader, A.F.; Jin, F.; Al-Tabbaa, A. Characterisation of reactive magnesia and sodium carbonate-activated fly ash/slag paste blends. Constr. Build. Mater. 2015, 93, 506-513. [CrossRef]

41. Shi, C.J.; Krivenko, P.V.; Roy, D. Alkali-Activated Cements and Concretes, 1st ed.; Chemical Industry Press: Beijing, China, 2008; pp. 70-74.

42. Kumar, S.; Kumar, R. Mechanical activation of fly ash: Effect on reaction, structure and properties of resulting geopolymer. Ceram. Int. 2011, 37, 533-541. [CrossRef]

43. Avirneni, D.; Peddinti, P.R.T.; Saride, S. Durability and long term performance of geopolymer stabilized reclaimed asphalt pavement base courses. Constr. Build. Mater. 2016, 121, 198-209. [CrossRef]

44. Francis, A.A. Crystallization kinetics of magnetic glass-ceramics prepared by the processing of waste materials. Mater. Res. Bull. 2006, 41, 1146-1154. [CrossRef]

45. Jeon, D.; Jun, Y.; Jeong, Y.; Oh, J.E. Microstructural and strength improvements through the useof $\mathrm{Na}_{2} \mathrm{CO}_{3}$ in a cementless $\mathrm{Ca}(\mathrm{OH})_{2}$-activated Class F fly ash system. Cem. Concr. Res. 2015, 67, 215-225. [CrossRef]

46. Thokchom, S.; Ghosh, P.; Ghosh, S. Effect of water absorption, porosity and sorptivity on durability of geopolymer mortars. J. Eng. Appl. Sci. 2009, 4, 28-34.

47. Hossain, M.M.; Karim, M.R.; Hossain, M.K.; Islam, M.N.; Zain, M.F.M. Durability of mortar and concrete containing alkali-activated binder with pozzolans: A review. Constr. Build. Mater. 2015, 93, 95-109. [CrossRef]

48. Habib, A.O.; Aiad, I.; Youssef, T.A.; Abd El-Aziz, A.M. Effect of some chemical admixtures on the physico-chemical and rheological properties of oil well cement pastes. Constr. Build. Mater. 2016, 120, 80-88. [CrossRef]

49. Zhang, Z.H.; Li, L.F.; Ma, X.; Wang, H. Compositional, microstructural and mechanical properties of ambient condition cured alkali-activated cement. Constr. Build. Mater. 2016, 113, 237-245. [CrossRef]

50. Huang, Q.; Wang, C.; Zeng, Q.P.; Yang, C.H.; Luo, C.Q.; Yang, K. Deterioration of mortars exposed to sulfate attack under electrical field. Constr. Build. Mater. 2016, 117, 121-128. [CrossRef]

51. Norambuena-Contreras, J.; Thomas, C.; Borinaga-Treviño, R.; Lombillo, I. Influence of recycled carbon powder waste addition on the physical and mechanical properties of cement pastes. Mater. Struct. 2016, 49, 5147-5159. [CrossRef]

52. Stora, E.; Bary, B.; He, Q.C.; Deville, E.; Montarnal, P. Modelling and simulations of the chemo-mechanical behaviour of leached cement-based materials Leaching process and induced loss of stiffness. Cem. Concr. Res. 2009, 39, 763-772. [CrossRef]

53. Heukamp, F.H.; Ulm, F.J.; Germaine, J.T. Mechanical properties of calcium-leached cement pastes: Triaxial stress states and the influence of the pore pressures. Cem. Concr. Res. 2001, 31, 767-774. [CrossRef]

54. Kuhl, D.; Bangert, F.; Meschke, G. Coupled chemo-mechanical deterioration of cementitious materials-Part II: Numerical methods and simulations. Int. J. Solids Struct. 2004, 41, 41-67. [CrossRef]

(C) 2016 by the authors; licensee MDPI, Basel, Switzerland. This article is an open access article distributed under the terms and conditions of the Creative Commons Attribution (CC-BY) license (http:/ / creativecommons.org/licenses/by/4.0/). 